\title{
Changing behavior to tackle the wildlife trade
}

I nternational trade in wildlife is a major threat to biodiversity conservation, with potentially adverse consequences for ecosystem functioning as well. It is of grave concern to governments and policy makers today as a result of marked and seemingly unsustainable levels of poaching and illicit trade, and the involvement of increasingly sophisticated criminal entities, which threatens the safety of rural communities, individual livelihoods, and national security in many countries. This trade involves many different high-value species, including African elephants, tigers, rhinos, pangolins, bears, and others that are in demand - most conspicuously in the Far East - either whole or for their parts and products, as luxury foods, traditional medicines, and curios.

Historically, responses to this problem have been predominantly regulatory and have involved the introduction of new and stronger legislation, the establishment of trade controls (including sanctions) within CITES, the Convention on International Trade in Endangered Species of Wild Fauna and Flora, and the use of diplomatic pressure. But with rising demand for high-value species - driven by growing wealth in parts of Southeast and East Asia, where wildlife consumption has long-standing cultural ties, and growing relative poverty of rural communities in the source countries of Africa and Asia - there is increasing recognition of the need for more multifaceted responses. Beyond stronger law enforcement and judicial procedures, these encompass engagement with local communities and support for sustainable livelihoods in wildlife source areas, along with a reduction in the demand for illegal wildlife products.

Although an integrated approach combining law enforcement, local community engagement, and demand-related management is ultimately required to address illicit trade, we are concerned about the overriding focus on countering illegal trade through enforcement and the criminalization of trade, and thereby the people who depend on it for their livelihoods. This was reiterated at CITES CoP16 in March 2013, and is exemplified by substantial investment in militarized approaches to conservation, the creation of the International Consortium on Combating Wildlife Crime, and the recent introduction of new legislation in source and consumer countries. Conservationists are often keen to demonstrate the success of these regulatory measures but are arguably guilty of misinterpreting policy movements for progress on the ground, and there is no question that poaching pressures are intensifying for many high-value species. Even though the exact scale of trade is unknown due to complexities in determining illegal trade volumes and the availability of illegal wildlife products in the marketplace, we do know that prices for pangolin, ivory, and rhino horn, for example, are rising fast. In our view, far more attention needs to be given to mainstreaming biodiversity conservation into broader livelihood policies and projects through collaborative engagement with local communities and supporting sustainable livelihoods. Crucially, however, we must better understand and manage demand. Although this has been explicitly recognized in numerous CITES resolutions (for example on bears, musk deer, and elephants), it is typically much less of a priority than regulation and is largely dependent on limited, external (eg non-governmental organization-based) funding. It is also hindered by a lack of in-depth and culturally sensitive understanding of both the demand for many species and the most appropriate interventions with which to influence and thereby change the behavior of illegal wildlife consumers.

Reducing demand is a huge challenge, but if we are to conserve species such as pangolins, tigers, and elephants we urgently require an intensive research effort into consumer preferences, beliefs, social norms, and lifestyles to inform and develop the most appropriate interventions. More specifically, where species are used in traditional medicines, this should include conducting research into substitutability, both with Western and alternative traditional remedies, and through collaboration with traditional Asian medicine practitioners. In the case of products of cultural importance, such as ivory, tiger parts, and luxury meats, research should examine the social norms driving procurement, the symbolic value and meaning of public consumption, and the wider social function of these products.

Notwithstanding the need for integrated approaches to address the illegal wildlife trade, in our view it is by understanding human behavior that we can begin to target consumers to change their preferences and purchasing behavior, for example through social marketing programs directed at consumers and at their social and professional networks, and thereby address the root of the problem directly. Despite the difficulties involved, we should therefore seek to measure the success of interventions, not just by the weight of regulation but also in terms of consumption.

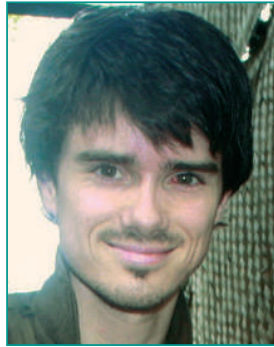

Daniel WS Challender DICE, University of Kent, UK

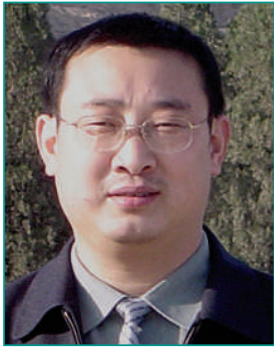

Shi Bao Wu South China Normal University, PR China

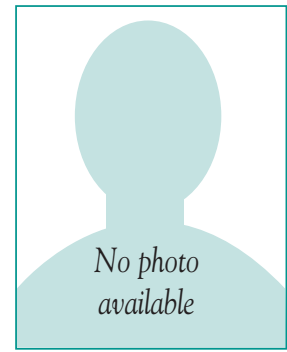

Vincent Nijman Oxford Brookes University, UK

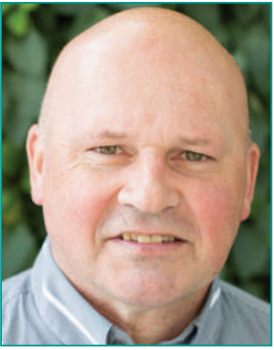

Douglas C MacMillan DICE, University of Kent, UK 